\title{
Kurt Salzinger - A Loss to Behavioral Science and to the World
}

\section{Francis Mechner ${ }^{1}$}

Published online: 28 February 2019

(C) Association for Behavior Analysis International 2019

Kurt Salzinger died tragically last November at the age of 88 in a New York subway fall that led to a fatal head injury. Kurt was not only a treasured friend and valued colleague, but also one of the few surviving remnants of the vanished culture that had shaped his values.

Kurt's dedication to truth and justice was familiar to many. In her speech at his memorial service, Kurt's wife Deanna spoke eloquently of his moral courage in taking principled stands. Her talk reminded me of incidents in W.N. Schoenfeld's seminar on verbal behavior that Kurt and I took in the Columbia University Psychology Department in the early 1950s. Schoenfeld was notorious for his way of provoking critical thought by making outrageous statements as if he believed them while challenging the class to refute them. "There is no real evidence for evolution," he might say. In the ensuing debates, Schoenfeld, a virtuoso at Socratic repartee, was an intimidating adversary. But it was always Kurt who, undaunted, intrepidly stood up to Schoenfeld. It was there that I first witnessed Kurt's propensity for taking principled stands, championing what he saw as the truth without regard to consequences. I could not help but remember that his father had been a lawyer in his native Vienna. A few years later, in the McCarthy era of the 1950s, Kurt defended a Columbia Assistant Professor who had been unfairly accused when others were afraid to stand up for him. The same dedication to truth and justice also manifested itself in Kurt's long and productive scientific career. Cut from the same cloth was his sharp eye for inconsistency, irony, and incongruity - the basis of his sophisticated and playful sense of humor. That sense of humor, and much of the rest of who Kurt was, and where he came from, is beautifully revealed in his autobiographical chapter published in 2016 by the Cambridge Center for Behavior Studies.

So, why do I describe Kurt as a remnant of a vanished culture? He and I, and some other behavioral scientists like Eric Kandel, grew up in the Vienna of the 1930s. Our parents were second-generation immigrants from the Austro-Hungarian empire's far-

Francis Mechner

fmechner@panix.com

1 Mechner Foundation, New York, NY, USA 
flung provinces. Vienna had been a magnet for the empire's Jews for close to a century, particularly for those who had been synthesizing the values of the Enlightenment with those of justice and learning, and often brought with them a disposition to challenge traditional ways of thinking - a disposition that Kurt had absorbed and then manifested with gusto. The Hapsburg Emperor Franz Joseph welcomed those immigrants to Vienna and allowed them and their offspring to create the Vienna of Ludwig Wittgenstein, Rudolf Carnap, Gustav Bergmann, Kurt Gödel, the Vienna circle, Otto Neurath, Sigmund Freud, Artur Schnitzler, Stefan Zweig, Otto Frankel, Victor Frankl, Paul Lazarsfeld, Arnold Schönberg, Fritz Kreisler, Gustav Mahler, Bruno Walter, Gustav Klimt, Max Perutz, Lise Meitner, and countless other pioneers who were driven by the urge to challenge and override prevailing ideas. Since many who grew up in that environment reflected its values, it is no wonder that Kurt and I were attracted to B.F. Skinner, W.N. Schoenfeld, F.S. Keller, and their naturalistic and empirical approaches to the study of behavior.

Though that culture's epicenter is long gone, its ripples continue to spread, as seen in the treasure trove of Kurt's legacy. That legacy includes his far-ranging contributions to the science of behavior in such areas as schizophrenia, verbal behavior, child development, and learning processes in various animal species, as well as his impact on the scientific organizations in which he played leadership roles, like the Cambridge Center for Behavioral Studies, the New York Academy of Science, the National Science Foundation, the American Psychological Association, the Eastern Psychological Association, and the Association for Behavior Analysis International of which he was once President. But perhaps the most enduring set of ripples is the outstanding family Kurt gave the world: his children and grandchildren - the next generations of thoughtful, committed, and creative people. Thank you, Kurt.

Publisher's Note Springer Nature remains neutral with regard to jurisdictional claims in published maps and institutional affiliations. 